\title{
9. LIFE CYCLE(S) OF SEDIMENT PHYSICAL PROPERTIES, CEARA RISE ${ }^{1}$
}

\author{
Timothy D. Herbert, ${ }^{2}$ Steven DiDonna, ${ }^{3}$ Franck Bassinot, ${ }^{4}$ Jens Gruetzner, ${ }^{5}$ and Kate Moran ${ }^{6}$
}

\begin{abstract}
Sediments recovered during Leg 154 exhibit an unusually wide variation of interbedded lithologies down to the deepest layers recovered (900-m burial depth). We report here on relations of properties as a function of lithology and burial depth. Lithologies have been characterized by a large number of carbonate determinations on samples used for discrete physical properties measurements. Carbonate determinations have been supplemented by quartz determinations using infrared spectroscopy, and by shipboard determinations of biogenic opal content. Physical properties show coherent patterns with carbonate content over discrete zones that average several hundred meters of thickness. The relation between seismic velocities and carbonate content is strong enough to detect a velocity calibration problem for an interval of Site 925 shipboard measurements.

The shallowest Ceara Rise sediments show a weak positive dependency of bulk density and a more pronounced positive relationship of seismic velocities on carbonate content. The difference between bulk-density and carbonate relations on Ceara Rise and well-known relations established in siliceous settings can be explained by the high quartz contents $(15 \%-16 \%$ on a carbonate-free basis) of the Pleistocene section.

For each type of physical property, inversions are encountered, where the sense of the correlation between property and lithology changes. For example, both bulk densities and seismic velocities become negatively correlated to carbonate content at depths of 100-250 meters below seafloor on the Ceara Rise, but then become positively correlated on further burial. These inversions are interpreted to result from the competition between mechanical and chemical compaction in pelagic sediments. Bulk density, in particular, shows a complex evolution with depth that often results in a parabolic relation of density to carbonate content in more deeply buried Ceara Rise sediments. Nevertheless, the relations between physical properties and carbonate content on Ceara Rise are sufficiently systematic that predictive models can be generated to relate lithology to signals sensed by borehole logging tools and by seismic imaging.
\end{abstract}

\section{INTRODUCTION}

Measurements of sediment physical properties describe in various ways the density of sediment particles, their packing relations, and connections between particles. These quantities are of fundamental importance to paleoceanographic, geochemical, and geophysical investigations of pelagic sediments. The dry bulk density of sediments, in addition to sedimentation rate, is a crucial parameter for reconstructing sediment fluxes over time. Paleoceanographers devote considerable effort to refining stratigraphies and to assessing uncertainties in dating that can affect sedimentation rate. Only some are aware, however, that variation in bulk density as a function of sediment type and burial depth can be an equally, and in some cases, more important component of the mass accumulation equation. Accurate characterization of diagenetic transformations in pelagic sediments also depends on a good understanding of physical properties. For example, diagenetic equations coupling reactions with diffusion through pore fluids require that diffusion coefficients be modified for porosity and tortuosity effects (cf. Berner, 1980). Stratigraphic variations in pelagic sediments can be imaged by seismic techniques, but here again good models relating physical properties such as bulk density and seismic velocity to both primary and diagenetic controls are essential for interpretation of reflection profiles (Mayer, 1979; Fulthorpe et al., 1989; Nobes et al., 1991).

${ }^{1}$ Shackleton, N.J., Curry, W.B., Richter, C., and Bralower, T.J. (Eds.), 1997. Proc. ODP, Sci. Results, 154: College Station, TX (Ocean Drilling Program).

${ }^{2}$ Department of Geological Sciences, Brown University, Providence, RI 02912, U.S.A. Timothy_Herbert@brown.edu

${ }^{3}$ Geoscience Research Division, Scripps Institution of Oceanography, La Jolla, CA 92093-0215, U.S.A.

${ }^{4}$ Centre des Faibles Radioactivites, 91198 Gif-sur-Yvette, France.

${ }^{5}$ GEOMAR, Wischhofstraße 1-3, D-24148 Kiel, Federal Republic of Germany.

${ }^{6}$ Bedford Institute of Oceanography, New Bedford, Canada.
Generalized curves of pelagic sediment physical properties trends with burial depth have been available for some time (Hamilton, 1974, 1976), but these do not do justice to the variability and structure of physical properties encountered by deep-sea sampling. The severe disturbance caused by rotary coring in the upper hundreds of meters of the sediment column damaged all but the most evident trends in physical properties data collected by the Deep Sea Drilling Project. Hydraulic piston coring by the Ocean Drilling Program (ODP) has revealed for the first time the full complexity of the physical evolution of pelagic sediments. It is now clear that initial differences in the fabric of pelagic sediments are related to differences in lithology, highfrequency variations in physical properties exist in the sediment column, and primary differences in physical properties persist through at least some stages of compaction (Mienert, 1984; Wilkens and Handyside, 1985; Mayer, 1991; Herbert and Mayer, 1991; Nobes et al., 1991; Rack and Palmer-Julson, 1992; Taylor, 1991). Some simple relations often apply. For example, the porosity and bulk density of equatorial Pacific sediments can be modeled as a mixing of two end-member types of material, carbonate and biosiliceous-terrigenous components, with characteristic packing geometries (Mayer, 1991; Herbert and Mayer, 1991). Variations in bulk density and seismic velocity as a function of depth in such settings are functions of the composition of the sediment (Lyle and Dymond, 1976; Mayer, 1979; Mienert, 1984; Nobes, 1989).

Sediments recovered by Leg 154 provide a chance to expand our knowledge of how physical properties variation is determined by lithological variability and diagenetic changes (Fig. 1). Leg 154 sediments are characterized by an essentially continuous alternation of lithologies at a decimeter scale, to burial depths approaching a kilometer (Fig. 1A). However, they are quite different from the mixed siliceous-carbonate sediments studied extensively in previous physical properties-sediment-type studies (e.g., Mayer, 1979; Mienert, 1984; Nobes et al., 1991; Rack and Palmer-Julson, 1992). Figure 1B displays corrected bulk densities (see below) measured on discrete sam- 
A

Figure 1. A. Estimated carbonate content (from calibration of color reflectance data to measured percent carbonate) at Site 925. Ceara Rise sediments consist of alternating beds of varying carbonate content. B. Variations in the initial bulk density and subsequent compaction behavior can influence physical properties trends with depth, such as the bulk density profile (estimated from discrete samples).

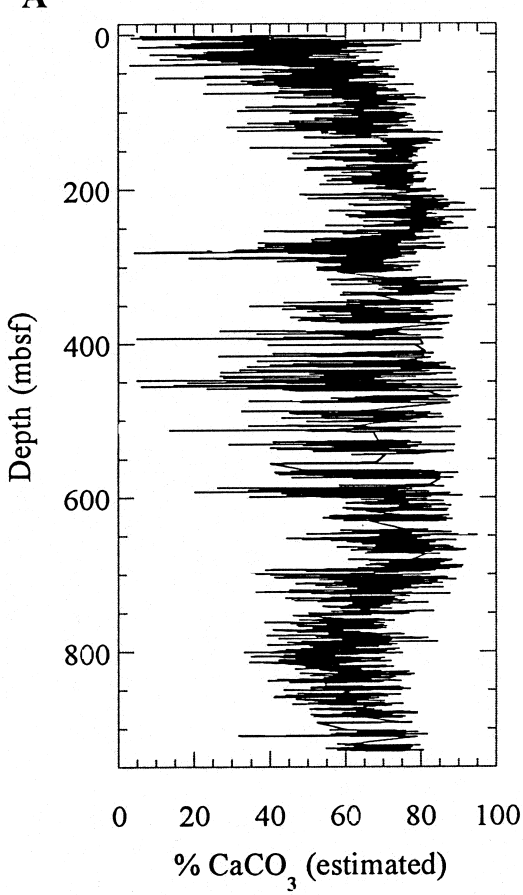

B

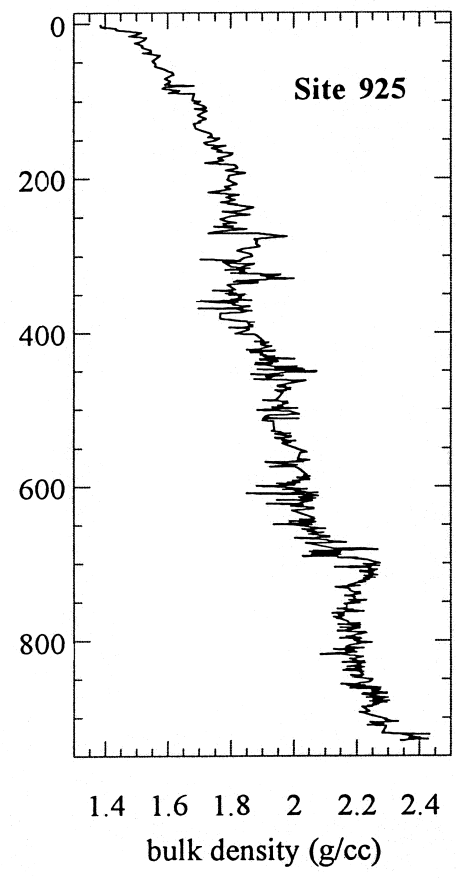

ample, the sediment switched from an overlying composition of nearly pure end-member lithology B to nearly pure end-member A. Typical scales for such physical properties inversions or anomalies are decimeters to several tens of meters.

Figure 3 shows typical relations between a simple index of lithology, carbonate content, and bulk density in near surface $(<20$ meters below seafloor [mbsf] burial depth) pelagic sediments from several locations. Each sediment province has a curvilinear relation between sediment bulk density and carbonate, with a different intercept at the carbonate-free end of the curve. The bulk density at the pure carbonate end-member is thus a pivot point; the bulk density of the noncarbonate components is the lever in the system. Grain density variations between major noncarbonate minerals in pelagic sediments are too small to cause the variability in bulk densities (Herbert and Mayer, 1991); rather packing geometry (porosity) must vary as a function of mineralogy (in mineralogy, we have grouped a number of related features such as grain size, grain shape, and electrostatic forces). The bulk densities of the noncarbonate fraction vary because the characteristic packing densities of opal (seen in data from the equatorial $\mathrm{Pa}$ cific) are different from a mixed opal-clay end-member (seen in data from the tropical Atlantic) and are further distinguished from the packing of a nearly pure clay end-member (north central Atlantic). Physical properties variations on the first scale, therefore, can arise simply by changing the sediment composition over time. For example, climatically driven carbonate-silica cycles in the equatorial $\mathrm{Pa}$ cific lead to substantial bulk density oscillations around the mean (Mayer, 1991; Herbert and Mayer, 1991; Hagelberg et al., 1995).

A second scale of inversion encountered on Ceara Rise occurs when boundaries in the burial cycle of sediments are crossed. In the latter case, the relation between lithology and physical properties changes sense over a transition zone of relatively short length (Fig. 2B). Note that inversion zones may occur when both end-members follow monotonic trends of physical properties with depth, but with different slopes; an abrupt change in physical properties with depth is not required. Systematic relations between physical properties and sediment type are again observed, but with opposite sense on either 


\section{Physical property}

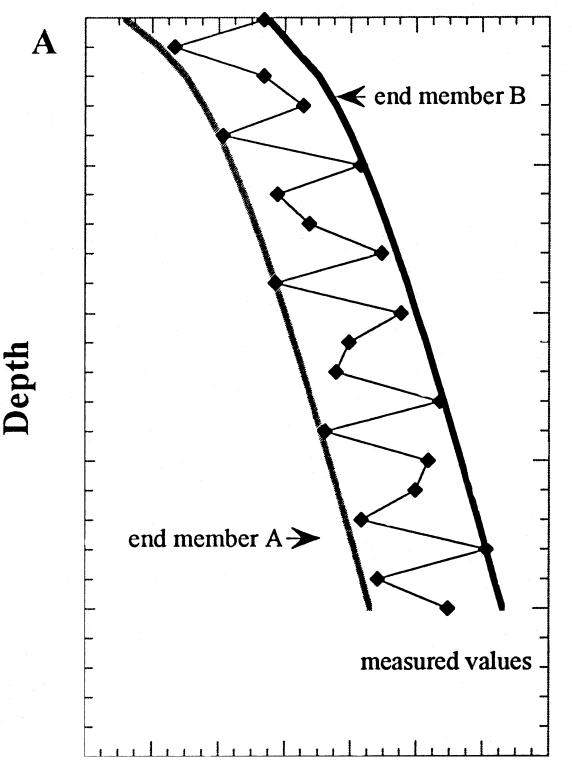

Physical Property

B

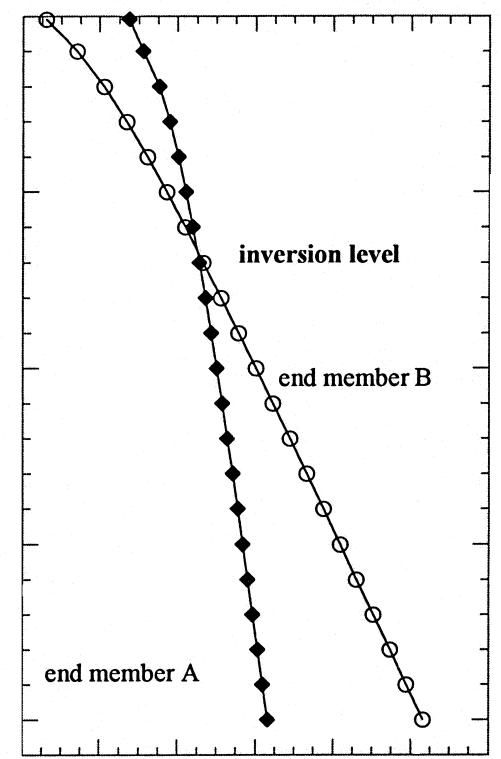

Figure 2. A. Idealized two-component system, where end-member lithologies have significantly different physical properties that evolve in parallel with depth. Oscillations in the measured property can be mapped as a mixing of the two end-member sediment types, with an appropriate depth correction. An example of such a system is the bulk density-carbonate relation in equatorial Pacific sediments. Sediment physical properties could be predicted from measurements of endmember percentages, or end-member percentages could be estimated from physical properties measurements. B. If the slopes of the end-member-physical properties curves as a function of depth are not parallel, then inversions can occur. Physical properties variations in the sediment column still match changes in the lithology, but with a different sense on opposite sides of the inversion zone.

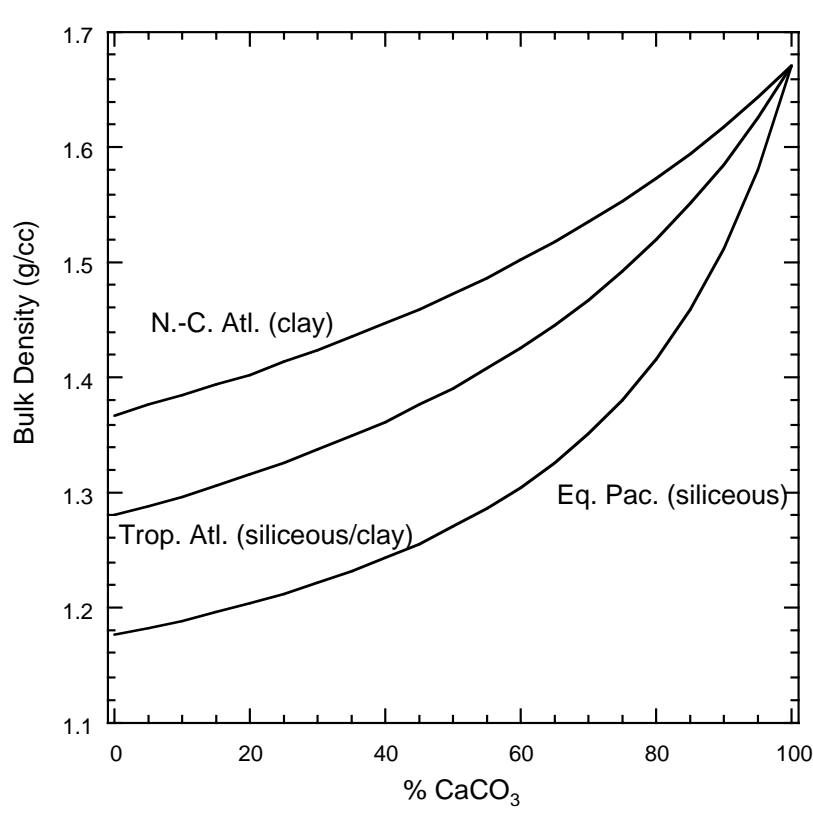

Figure 3. Typical bulk density-carbonate relations seen in uncompacted pelagic sediments with different noncarbonate components (following Herbert and Mayer, 1991). The greatest sensitivity of bulk density to carbonate content occurs in the highly siliceous equatorial Pacific sediments; lower sensitivities in other settings reflect the absence of opaline silica and the admixture of quartz. Equatorial Pacific (Eq. Pac.) data modeled from results of DSDP Leg 85 and ODP Leg 138, tropical Atlantic (Trop. Atl.) data modeled from results of ODP Leg 108, and north-central Atlantic (N.-C. Atl.) data modeled from results of DSDP Leg 94.

side of the inversion. These inversions are highly significant, because erroneous application of rules developed from sampling one interval of the sediment column could seriously misrepresent the physical state of the other, and could confound efforts to predict lithologies from physical properties information. Zones bounded by such physical properties inversions are typically hundreds of meters thick in
Ceara Rise sediments, although the surficial bulk density-carbonate inversion is accomplished within $40 \mathrm{~m}$ of the sediment-water interface (see below).

We contend that the simplest way of relating physical properties variations to lithology in Ceara Rise sediments is by measuring or estimating carbonate content. We recognize that using carbonate as the master variable hides many details of importance-for example, grain size, clay mineralogy, and others. Indeed, the presence of biosiliceous material in intervals of the middle Miocene and early Oligocene/late Eocene at Ceara Rise significantly alters the carbonatephysical properties relations at Site 929 (Curry, Shackleton, Richter, et al., 1995). Nevertheless, we will show that most variance of physical properties variations as a function of burial depth in sediments similar to those recovered by Leg 154 can be described by measuring or estimating carbonate content. We have implicitly assumed that either noncarbonate mineralogy does not change substantially downsection or that such changes do not affect physical properties trends to a significant degree.

\section{METHODS}

\section{Carbonate Content and Noncarbonate Mineralogy}

Carbonate determinations are taken from shipboard measurements through coulometric determinations made at the Scripps Institution of Oceanography (SIO) and from those of other shore-based studies. For this study, we concentrated on determining carbonate contents on the same samples used for bulk density and seismic velocity analyses at Site 925 . In addition, we used proxy measurements of carbonate to substantiate the results obtained from Site 925 at other Ceara Rise sites. Calibrations of reflectance, natural gamma counts, and magnetic susceptibility to carbonate content can be made by relating the proxy measurements to discrete carbonate measurements. Both natural gamma measurements and magnetic susceptibility are volume measurements; carbonate content is naturally a weight measure. The significance of a given natural gamma count or susceptibility reading is rather different in surficial sediments, which contain nearly $80 \%$ water by volume, as compared to the same measurement in lithified sediments. Rather than applying a continuous porosity correction to natural gamma and magnetic susceptibility data, we have chosen to use color reflectance, which seems not to require a po- 
rosity adjustment, as our index of carbonate content. We use a stretched exponential fit of reflectance at $700 \mathrm{~nm}$ to carbonate content at each site (of the form $R=\mathrm{C}_{1}+\exp \left(\% \mathrm{CaCO}_{3} \cdot \mathrm{C}_{2}\right)$. The typical correlation coefficient of the fits is about 0.9 .

Because previous work suggested that quartz in pelagic sediments can significantly reduce porosity in comparison to a pure clay matrix (Herbert and Mayer, 1991), we also estimated the quartz percentage (on a carbonate-free basis) of 50 samples from Site 925. Samples were made into $\mathrm{KBr}$ disks by mixing powdered, carbonate-free residue with spectroscopic grade $\mathrm{KBr}$ at a ratio of $0.5 \%$ sample to $99.5 \%$ $\mathrm{KBr}$. Disks were analyzed using a Perkin-Elmer Fourier Transform Infrared (FTIR) spectrometer. To estimate quartz content, we used absorbance at wavenumbers 800 and $780 \mathrm{~cm}^{-1}$, calibrated to finely ground quartz standards (Herbert et al., 1992). Analyses of replicate disks suggest that the FTIR method provides results with a relative uncertainty of about $5 \%$.

Biogenic opal estimates were obtained from shipboard geochemical determinations, shipboard smear-slide estimates, and FTIR analyses at SIO of selected Site 925 samples. Only a small fraction of the sections studied contain appreciable $(10 \%-30 \%$ on a carbonate-free basis) amounts of biogenic silica.

\section{Edited MST Data}

Both gamma-ray attenuation porosity evaluator (GRAPE) density and $P$-wave logger data from Leg 154 suffered from calibration problems. In addition, the GRAPE detector often showed periods of erratic behavior suggestive of power supply problems and of electrical interference with other MST sensors. GRAPE data are still useful, provided that they are carefully edited with an eye to agreement with discrete measurements, to continuity of data, and to agreement with values obtained on offset holes. The data evaluated here have been screened to edit the effects of core disturbance (most frequently encountered in the top 20-75 cm of advanced hydraulic piston corer $[\mathrm{APC}]$ and extended rotary barrel $[\mathrm{XCB}]$ cores), fractures, and instrumental malfunctions. Where multiple GRAPE determinations were made on one point of a core, as happened during the long counting times for natural gamma measurements, we found that the GRAPE density tended to increase from beginning to end. After carefully comparing data for internal consistency with GRAPE estimates just before and after the interval of multiple recordings, and for consistency with discrete measurements, we decided to discard all replicate values except the last. The cause for drift is unknown, but may involve sensor interference.

$P$-wave logger data need to be continuously adjusted to discrete measurements to give reliable low-frequency estimates of velocities (see Grutzner et al., this volume). However, because we are especially interested in the relative sense of velocity anomalies with changes in lithology, we found that $P$-wave logger measurements were very useful for confirming at high resolution the velocity-carbonate relations that will be detailed later using discrete measurements.

\section{Bulk Density-Porosity Relations}

Volumes used to compute densities during the Leg 154 cruise were determined by three methods: by pycnometer in the shallowest parts of the recovered sections, by constant-volume cylinder in somewhat more consolidated intervals, and by measuring the dimensions of sawed cubes in more lithified sections. Dry density and mineral grain density are indirectly determined from wet and dry weights and the volume estimates. The variance of grain density estimates is a good indication of measurement accuracy, because with only a few exceptions (not typical of the dominant components of most Leg 154 sediments), the grain density of common pelagic sediment minerals ranges from 2.6 to $2.7 \mathrm{~g} / \mathrm{cm}^{3}$. Large scatter and implausible grain densities usually indicate volume and/or weight measurement errors. We observe the largest deviations in samples analyzed for wet volume by pycnometer: calculated grain densities range as high as $3.40 \mathrm{~g} / \mathrm{cm}^{3}$ and as low as $2.3 \mathrm{~g} / \mathrm{cm}^{3}$ in the upper $100 \mathrm{mbsf}$ of sediment (Curry, Shackleton, Richter, et al., 1995).

We suspect that the pycnometer may not always produce reliable estimates of wet volume and have modified some density estimates from those reported in the Initial Reports volume. More detailed analyses than ours have indicated that pycnometer results on wet samples often give internally inconsistent and suspect results for index properties (O'Brien and Manghnani, 1992; Nobes et al., 1992; Bassinot et al., 1993). However, Nobes et al. (1992) confirm that the pycnometer gives accurate volume determinations on dry samples. As a check on grain densities, we measured the dry volume of a number of samples with the pycnometer (Table 1). With the exception of a few samples rich in biosiliceous material (Cores 154-929A-51X and $52 \mathrm{X}$ ), all gave estimates of almost exactly $2.7 \mathrm{~g} / \mathrm{cm}^{3}$. Therefore, we have reestimated bulk density using this measured grain density and the wet and dry weights of physical properties samples according to the following relations:

$$
\begin{gathered}
\text { Porosity }(\phi)=(W W-D W) \cdot(G D) /([W W-D W] \cdot G D \\
+D W \cdot[G D-1.025]-W W \cdot 0.025),
\end{gathered}
$$

$$
\text { Dry density }=(1-\phi) \cdot G D \text {, }
$$

and

$$
\text { Bulk density }=(1-\phi) \cdot G D+\phi \cdot 0.025 \text {, }
$$

where $W W$ is the measured wet weight of the sample, $D W$ is the weight after drying at $100^{\circ} \mathrm{C}$ overnight, $G D$ is the average mineral grain density, $1.025 \mathrm{~g} / \mathrm{cm}^{3}$ is the density of seawater, and 0.025 is the contribution of sea salt to pore fluid density.

GRAPE estimates of bulk density can be converted to dry density or porosity estimates using our measured average of $2.7 \mathrm{~g} / \mathrm{cm}^{3}$ for average grain density at Ceara Rise (see Boyce [1976] or Herbert and Mayer [1991] for equations relating bulk, dry, and grain densities). It is important to note that in most cases the differences between our new estimates and shipboard results are small. The primary effect is to reduce erroneous variance in calculations of bulk density, dry density, and porosity. This increase in precision gives an important gain in detecting the lithologic dependence of relatively small (order of $2 \%-3 \%$ around the mean) deviations of discrete bulk densities from a monotonic function of depth.

\section{EVOLUTION OF PHYSICAL PROPERTIES Bulk Density-Porosity}

Contrary to the results of ODP drilling in many other locations, there is not a strong positive relationship between bulk density and carbonate content on the Ceara Rise, and what relationship does exist quickly inverts in the zone of mechanical compaction. GRAPE density logs cannot be used to estimate carbonate content reliably for Leg 154 cores, as they can elsewhere (cf. Mayer, 1991; Herbert and Mayer, 1991; Hagelberg et al., 1995). Why does the frequent density-carbonate relationship fall apart on Ceara Rise? There appear to be two main reasons. First, the Ceara Rise sediments are unusually "muddy"-carbonate contents in the upper $10 \mathrm{mbsf}$ do not exceed $50 \%$, and average only about $30 \%$. A glance at established carbonate-density relations reveals that bulk density is generally not a very sensitive index of carbonate content below $50 \%$ in most settings because of the curvilinear form of the relation (Fig. 3). A second, and perhaps decisive factor, is the presence of large amounts of terrigenous quartz in Ceara Rise surficial sediments. Our FTIR results indicate that an average of $16 \%$ of the noncarbonate fraction consists of quartz over the 
Table 1. Grain densities measured by pycnometer on dry samples.

\begin{tabular}{|c|c|c|c|c|}
\hline $\begin{array}{l}\text { Core, section, } \\
\text { interval }(\mathrm{cm})\end{array}$ & $\begin{array}{l}\text { Depth } \\
\text { (mbsf) }\end{array}$ & $\begin{array}{c}\text { Mass } \\
(\mathrm{g})\end{array}$ & $\begin{array}{l}\text { Volume } \\
\left(\mathrm{cm}^{3}\right)\end{array}$ & $\begin{array}{c}\text { Grain } \\
\text { density } \\
\left(\mathrm{g} / \mathrm{cm}^{3}\right)\end{array}$ \\
\hline \multicolumn{5}{|l|}{ 154-926B- } \\
\hline $9 \mathrm{H}-5,107-109$ & 80.57 & 9.303 & 3.3846 & 2.749 \\
\hline $22 \mathrm{H}-3,121-123+$ & $209.89+$ & 23.170 & 8.561 & 2.706 \\
\hline & & & & \\
\hline $25 \mathrm{H}-3,61-63$ & 229.11 & 12.064 & 4.448 & 2.713 \\
\hline $27 \mathrm{H}-5,117-119$ & 251.67 & 11.35 & 4.249 & 2.671 \\
\hline $29 X-1,40-42$ & 259.40 & 9.99 & 3.615 & 2.763 \\
\hline $29 \times-4,74-76$ & 264.24 & 11.909 & 4.470 & 2.663 \\
\hline & 266.48 & 10.438 & 3.814 & 2.737 \\
\hline $32 X-7,10-12$ & 297.10 & 11.99 & 4.426 & 2.709 \\
\hline $34 \mathrm{X}-1,102-104$ & 308.32 & 11.746 & 4.322 & 2.718 \\
\hline $34 \mathrm{X}-3,141-143$ & 311.71 & 12.42 & 4.665 & 2.662 \\
\hline $35 X-1,117-119$ & 318.07 & 10.15 & 3.721 & 2.725 \\
\hline $35 X-2,58-60$ & 318.98 & 11.638 & 4.303 & 2.705 \\
\hline $36 \mathrm{X}-1,137-139$ & 328.81 & 12.99 & 4.848 & 2.680 \\
\hline $36 \mathrm{X}-4,25-27$ & 331.25 & 12.760 & 4.7106 & 2.709 \\
\hline $41 \mathrm{X}-1,53-55$ & 374.93 & 11.98 & 4.462 & 2.685 \\
\hline $49 \mathrm{X}-4,40-42$ & 456.6 & 11.505 & 4.231 & 2.719 \\
\hline $50 X-5,132-134$ & 468.73 & 15.466 & 5.683 & 2.721 \\
\hline $50 X-6,25-27$ & 469.16 & 15.051 & 5.559 & 2.713 \\
\hline $55 \mathrm{X}-4,47-49$ & 514.47 & 17.27 & 6.382 & 2.706 \\
\hline $56 X-6,55-57$ & 527.25 & 16.526 & 6.111 & 2.704 \\
\hline $58 \mathrm{X}-3,148-150$ & 542.98 & 12.03 & 4.435 & 2.713 \\
\hline $58 \mathrm{X}-1,120-122$ & 539.71 & 15.13 & 5.6331 & 2.686 \\
\hline $60 X-1,46-48$ & 558.37 & 18.58 & 6.890 & 2.697 \\
\hline \multicolumn{5}{|l|}{$154-926 \mathrm{C}-$} \\
\hline $\begin{array}{l}3 \mathrm{H}-2,81-83+ \\
\quad 4 \mathrm{H}-2,114-116\end{array}$ & $\begin{array}{r}21.81+ \\
31.64\end{array}$ & 16.652 & 6.158 & 2.704 \\
\hline $\begin{array}{c}17 \mathrm{H}-5,139-141+ \\
18 \mathrm{H}-3,46-48\end{array}$ & $\begin{array}{r}159.89+ \\
165.46\end{array}$ & 22.651 & 8.273 & 2.738 \\
\hline \multicolumn{5}{|l|}{ 154-929B- } \\
\hline $24 \mathrm{X}-7,39-41$ & 223.59 & 14.012 & 5.16 & 2.716 \\
\hline $26 \mathrm{X}-2,53-55$ & 235.13 & 16.356 & 6.105 & 2.679 \\
\hline $27 \mathrm{X}-4,145-147$ & 249.15 & 14.423 & 5.265 & 2.739 \\
\hline 29X-CC, 5-7 & 267.43 & 13.11 & 4.876 & 2.689 \\
\hline $31 \mathrm{X}-1,42-44$ & 281.92 & 17.215 & 6.371 & 2.702 \\
\hline $31 \mathrm{X}-6,70-72$ & 289.70 & 15.35 & 5.734 & 2.677 \\
\hline $32 X-2,114-116$ & 293.84 & 11.66 & 4.373 & 2.666 \\
\hline $44 X-5,141-143$ & 413.81 & 15.76 & 5.852 & 2.693 \\
\hline $44 X-6,142-144$ & 415.32 & 15.56 & 5.700 & 2.729 \\
\hline $46 \mathrm{X}-4,144-146$ & 430.48 & 14.256 & 5.251 & 2.715 \\
\hline \multicolumn{5}{|l|}{ 154-929A- } \\
\hline $25 \mathrm{X}-4,126-128$ & 229.76 & (1) & $\begin{array}{l}3.687 \\
7.538\end{array}$ & 2.677 \\
\hline $35 \mathrm{X}-6,63-65$ & $\begin{array}{l}328.53 \\
330.07\end{array}$ & 20.418 & 7.538 & 2.709 \\
\hline $36 \mathrm{X}-1,97-99$ & 330.97 & 21.33 & 7.801 & 2.734 \\
\hline $37 X-6,39-41$ & 347.59 & 12.60 & 4.675 & 2.695 \\
\hline $41 X-1,75-77$ & 378.85 & 13.80 & 5.103 & 2.704 \\
\hline $44 \mathrm{X}-3,26-28$ & 410.26 & 18.368 & 6.825 & 2.691 \\
\hline $44 \mathrm{X}-4,101-103$ & 412.61 & 16.07 & 5.93 & 2.695 \\
\hline $47 X-3,59-61$ & 439.69 & 12.88 & 4.744 & 2.698 \\
\hline $48 \mathrm{X}-2,42-44$ & 447.62 & 15.50 & 5.810 & 2.668 \\
\hline $51 X-4,44-46$ & 479.54 & 13.77 & 5.177 & 2.660 \\
\hline $51 X-5,104-106$ & 481.64 & 13.697 & 5.267 & 2.601 \\
\hline $51 X-6,15-17$ & 482.25 & 9.482 & 3.763 & 2.52 \\
\hline $52 \mathrm{X}-1,26-28$ & 484.46 & 13.34 & 5.237 & 2.547 \\
\hline $52 \mathrm{X}-6,30-32$ & 492.00 & 16.018 & 6.112 & 2.620 \\
\hline $\mathrm{X}-2,70-72$ & 495. & 17.2 & 5.93 & 2.886 \\
\hline $53 \mathrm{X}-4,12-14$ & 498.13 & 19.545 & 7.289 & 2.681 \\
\hline $54 \mathrm{X}-3,14-16$ & 506.34 & 11.873 & 4.402 & 2.697 \\
\hline $54 \mathrm{X}-4,94-96$ & 508.64 & 15.22 & 5.641 & 2.698 \\
\hline \multicolumn{5}{|l|}{ 154-929B- } \\
\hline $6 \mathrm{H}-2,20$ & $49.18+$ & 17.00 & 6.277 & 2.708 \\
\hline & 52.81 & & & \\
\hline
\end{tabular}

Note: $+=$ composite of two or more samples at indicated depths.

upper 200 mbsf at the Ceara Rise drill sites. Unlike clay minerals, quartz tends to produce a tight packing fabric. One of the prime factors that can differentiate the packing of carbonate-rich and carbonate-poor pelagic sediments is therefore greatly reduced at the Ceara Rise. Thus, although there is demonstrably an initial positive correspondence between bulk density anomalies and positive excursions in estimated carbonate content in Leg 154 records (Figs. 4, 5), it is weak. It seems likely that it is the high quartz content of Ceara Rise sediments that leads to the first of the larger scale inversions in sediment-physical properties relationships observed on Leg 154.
The first 100 mbsf of the sediment column on Ceara Rise has a rapid increase in bulk density (Fig. 1B). To separate the effect of decimeter-scale variations in carbonate content from gradual compactional effects, we fit a smooth spline function to GRAPE profiles, and recalculated GRAPE variations as anomalies from the trends. We used GRAPE and reflectance data because discrete measurements were too sparse to capture the depth evolution of bulk density in the upper 100 mbsf. Deviations of individual bulk density measurements from a smooth trend give negative anomalies if the measured sample is less dense (more porous) than expected and positive if it more dense (less porous). When anomalies are compared to estimated carbonate content in 10-m windows of data, it becomes clear that the initial weak positive correlation of bulk density to carbonate content becomes inverted to a stronger, negative correlation with a few tens of meters of burial (Fig. 5). A transition zone from about 30 to $60 \mathrm{mbsf}$ at Hole 929A shows large scatter before the deeper relationship becomes well defined. This changing sense of the bulk density-carbonate relationship indicates that mechanical compaction by rearrangement of grains proceeds more efficiently in the less calcareous intervals in Ceara Rise sediments. The tighter packing of carbonate-poor intervals below the inversion is, we suspect, greatly enhanced by the abundance of quartz (note that the internal porosity provided by biogenic carbonate particles may also play a role in creating relative differences in porosity and bulk density at depth, but that our conclusion that the carbonate-free layers suffer relatively more mechanical compaction remains valid).

Two processes determine the density and porosity at a given depth. Mechanical compaction becomes significant within 10-20 m of the surface, and favors compaction of the less calcareous zones in Ceara Rise sediments (Fig. 5), with the exception of siliceous intervals. Note that by $100-\mathrm{m}$ burial depth, a pure carbonate would be less dense by about $0.15 \mathrm{~g} / \mathrm{cm}^{3}$ than would a clay and/or quartz end-member. Associated signatures of mechanical compaction are increased seismic velocities and increased seismic anisotropy (see below). Chemical compaction, which favors more calcareous intervals, does not become a significant porosity-reducing process until a burial depth of at least $300 \mathrm{~m}$. In addition to affecting bulk density and porosity, chemical compaction increases seismic velocities without increasing anisotropy. Because the mechanical and chemical processes operate with different depth dependencies, a rather complex relation between bulk density and carbonate content results.

To trace the evolution of compaction in the more deeply buried section of Ceara Rise, we compared bulk density anomalies to measured carbonate content at Site 925 over 50-m windows. In this case, we computed anomalies from a linear fit of discrete bulk density data to depth. We present selected windows from Holes 925A in Figure 6. Data from the other deep hole (929E) are not plotted but show similar features. What is evident is that bulk density generally varies systematically with carbonate content, but with a changing form with depth. From depths below the first significant density inversion (about 30 mbsf on Ceara Rise) to about 200 mbsf, bulk density is negatively, and nearly linearly, correlated to carbonate content (Fig. 5). With progressive burial, the relation becomes more evidently nonlinear (Fig. 6). The highest bulk densities and the lowest porosities occur for carbonate contents of $40 \%-50 \%$ between 200 and 300 mbsf at Hole 925B (Fig. 5). From 350 to 400 mbsf at Hole 925A, bulk density is highest at carbonate contents of $50 \%-70 \%$, and rolls off steeply to lower values in more calcareous intervals. A similar relation holds true for the interval shown from 550 to $600 \mathrm{~m}$, with the exception that the position of maximal density has shifted to sediment of between $70 \%$ and $80 \%$ carbonate content. The low-carbonate limb of the parabola becomes very clear by $750-\mathrm{m}$ burial depth, and by the base of the hole, the relationship is a nearly linear trend of increasing bulk density with increasing carbonate content. We suspect, but we cannot prove with the existing data, that had sediment of extremely high carbonate content been recovered in the deepest part of the hole, it may 
Figure 4. In the shallowest parts of the Ceara Rise sections, bulk density is weakly correlated to carbonate content. Here, negative magnetic susceptibility is plotted as a carbonate proxy. Note that positive GRAPE bulk density anomalies correspond to more calcareous layers.

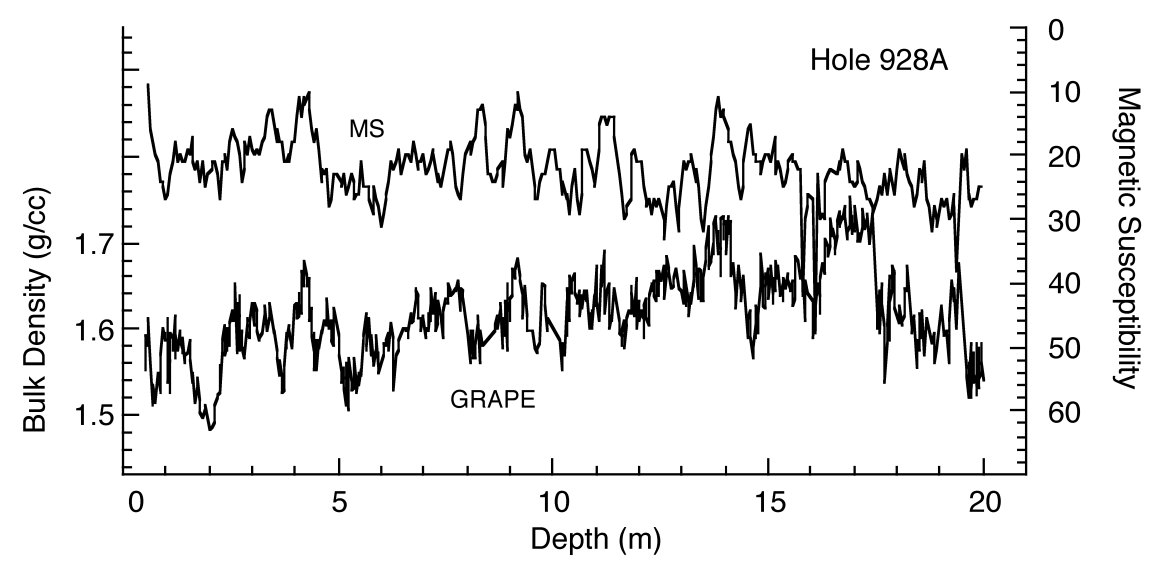

er pelagic settings (Mayer, 1979; Mienert, 1984; Fig. 7). An inversion zone develops over a range of about $30 \mathrm{~m}$; below about $100 \mathrm{~m}$, velocities are negatively correlated with carbonate content for a significant interval (Fig. 7). The depth at which the carbonate-velocity relationship inverts is substantially greater than that of the bulk density-carbonate relationship. This suggests that a significant amount of mechanical compaction is required to couple grains in carbonatepoor intervals to achieve seismic velocities greater than those in adjacent carbonate-rich layers.

A final reversal of the seismic velocity-lithology relationship appears to coincide with the onset of chemical compaction (Figs. 8, 9). By about 300-mbsf burial depth at Sites 925 and 929, longitudinal velocities become positively correlated to carbonate content. Note that we plot uncorrected velocities because we are most interested in the sense of the relationship and do not wish to include the effect of the thermal gradient on pore-water velocities. Through most of the remaining section, the relationship is nearly linear (Fig. 8). This linearity is almost certainly deceiving, because the extrapolated velocities at $0 \%$ carbonate become unrealistically low in the deepest part of the Site 925 section. A more plausible scenario is that a complete regression would have a stretched exponential form (with an intercept of, for example, about $1900 \mathrm{~m} / \mathrm{s}$ at $0 \%$ carbonate at $900 \mathrm{mbsf}$ ), with only a small deviation from linearity in the range of lithologies we sampled (carbonate contents from $40 \%$ to $90 \%$ ). As burial depth increases, the sensitivity of longitudinal velocities to carbonate content increases substantially. We attribute this change to the positive relationship between carbonate content and pressure solution. Transverse velocities below 300 mbsf (Fig. 9) show a similar positive relationship to carbonate content, but with considerably more scatter than for longitudinal velocities. Note that the slope of the transverse velocity dependence on carbonate content is always lower than it is for the longitudinal velocity.

The correlation of velocity to carbonate content is so clear that we think it can be used to correct a calibration error in velocity measurements at Hole 925A (Fig. 10). Shipboard data show an abrupt shift to lower velocities (by $300-400 \mathrm{~m} / \mathrm{s}$ ) beginning at Core $154-925 \mathrm{~A}-11 \mathrm{R}$ (Curry, Shackleton, Richter, et al., 1995). The drop corresponds to a recalibration of velocity measurements with a change of personnel (the delay time used to compute velocities was changed). A corresponding shift to higher velocities is indicated at Core 154-925A-51R to the base of the hole, and also coincides with an instrument calibration change. There is no indication of any abrupt lithologic change at these depths. Borehole velocity measurements do not agree well with shipboard data over the interval. In fact, the zone from Cores 154925A-11R through 50R shows a consistent offset between laboratory measurements and seismic velocities estimated from wireline logs (Curry, Shackleton, Richter, et al., 1995), with discrete data 300-400 $\mathrm{m} / \mathrm{s}$ lower than suggested by logs. We conclude that the velocity data from Cores 154-925A-11R through 50R must be corrected. We use linear regressions of velocities to carbonate content from 360 to 375 

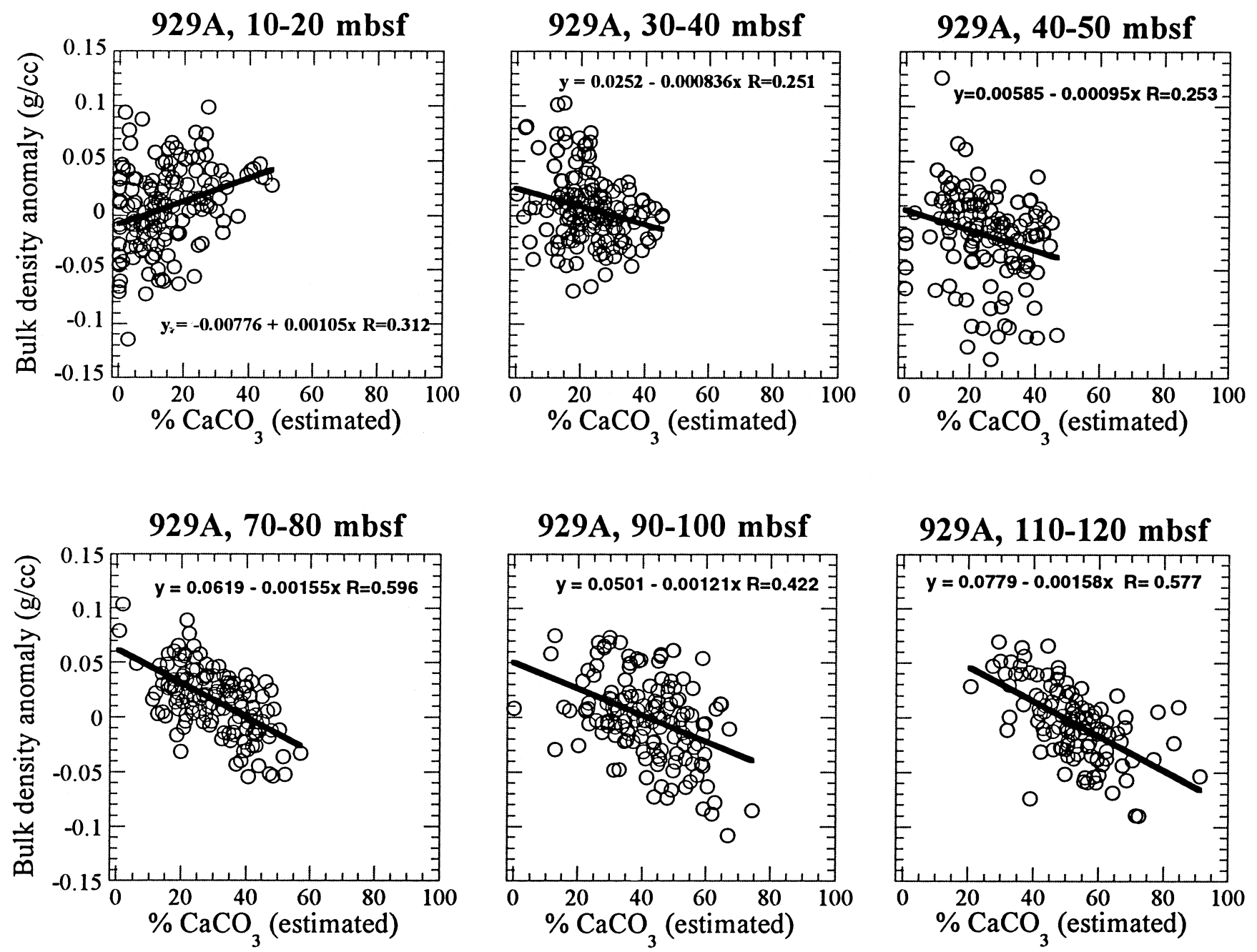

Figure 5. Evolution of bulk density anomalies (estimated by GRAPE) at Hole 929A as a function of depth and carbonate content (estimated by percent reflectance at $700 \mathrm{~nm}$ ). Note the inversion from a weakly positive relation to estimated carbonate content to a clearly negative relation by 30 -m burial depth. This relatively shallow onset of preferential mechanical compaction in carbonate-poor layers is enhanced by the high quartz content of Ceara Rise sediments.

mbsf (just above the delay time adjustment) and from 380 to 400 mbsf (just below the adjustment) (Fig. 10). The correlation coefficients are 0.94 and 0.98 , respectively, which we think will provide a firm basis for correcting the Hole $925 \mathrm{~A}$ velocities measured on discrete samples. We propose that lab measurements from Cores 154925A-11R through 50R be adjusted according to the model:

$$
V(\text { adj })=262 \mathrm{~m} / \mathrm{s}+1.1 \cdot \text { V(shipboard }) \text {. }
$$

At this point, we can evaluate the relative importance of lithologically dependent physical properties on seismic reflection profiles of Ceara Rise sediments. Seismic reflectors arise from changes in impedance as a function of depth:

$$
I_{(z)}=p_{(z)} V_{(z)}
$$

where $p_{(z)}$ is the bulk density at a given depth, and $V_{(z)}$ is the corrected longitudinal seismic velocity. Whether a change in lithology will manifest itself seismically depends on whether lithologic dependencies of bulk density and seismic velocity oppose or reinforce each other, how much the parameters vary, and the length scale of the anomaly relative to the seismic source frequency. Analysis of the Ceara Rise data indicate that the seismic velocity component of the impedance equation should dominate the reflection signal. Bulk density anomalies, although showing significant structure in relation to carbonate content, vary by about $5 \%$ around the mean defined by a smooth trend with depth. Seismic velocities can vary by up to $25 \%$ around the local mean. The changing sense of the bulk density and velocity relations introduce some subtleties in the interpretation of reflection profiles. Shallow $(<30 \mathrm{~m})$ reflections on the Ceara Rise should result from the combined effects of bulk density and velocity; both vary positively with carbonate content. Over a depth range from about 30 to $100 \mathrm{mbsf}$ on Ceara Rise, bulk density and seismic velocity components of the impedance profile tend to oppose each other: the bulk density term is larger in carbonate-poor intervals, which tend to have lower velocities. From a burial depth of about 100-250 m, the two physical properties reinforce each other (both generally lower in high carbonate intervals), and carbonate fluctuations should have a clearer seismic expression on Ceara Rise. Below about $300 \mathrm{~m}$, bulk densities display a parabolic relation to carbonate content, whereas the seismic velocity relation is overwhelmingly positive. As indicated above, the velocity term should dominate the 

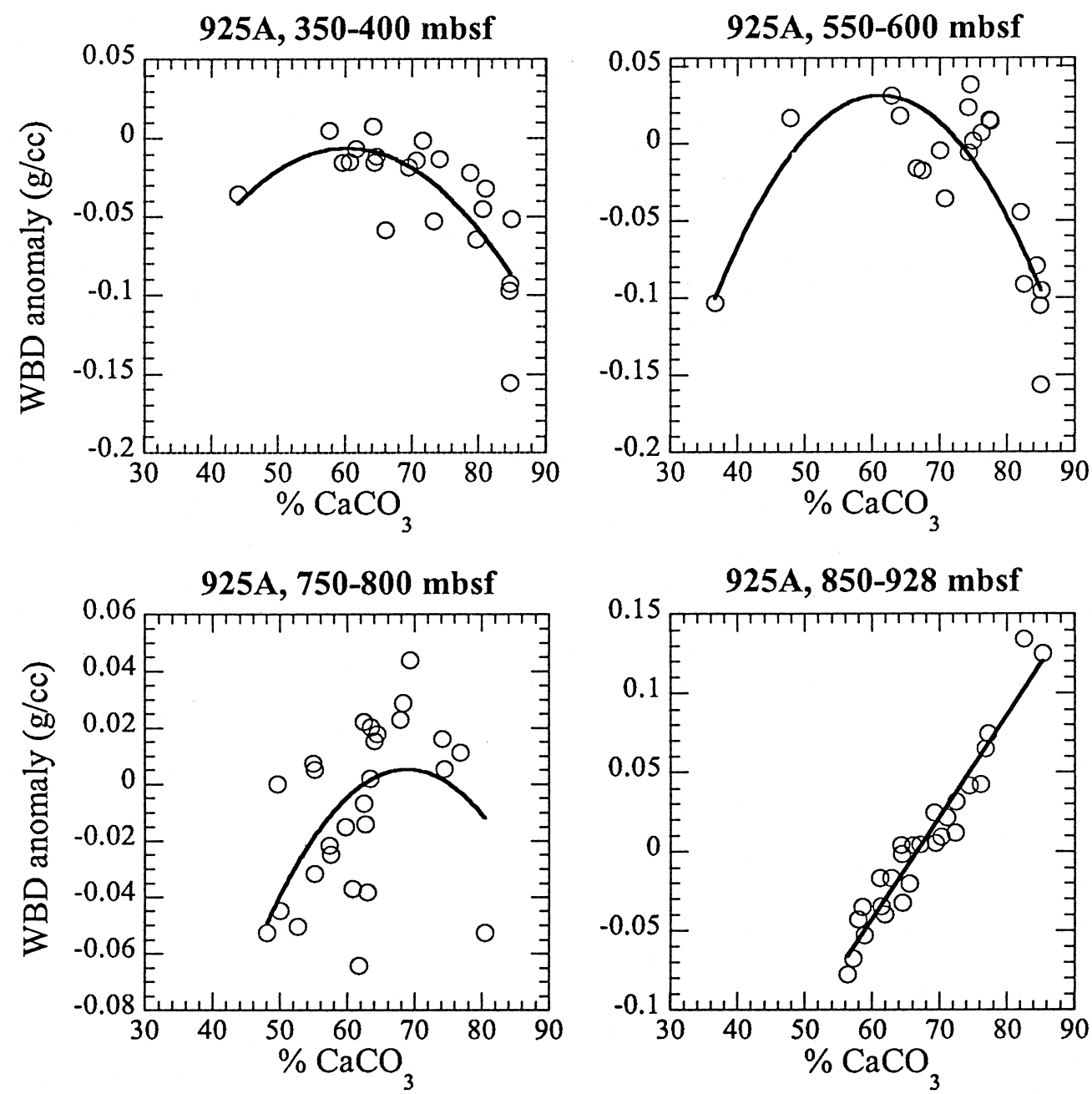

Figure 6. Evolution of bulk density anomalies, measured on discrete samples at Hole 925A, as a function of depth and measured carbonate content. Note that in contrast to the more shallowly buried Ceara Rise section (Fig. 5), the relations seem to follow an asymmetric parabolic shape (convex upward). The locus of the most positive bulk density anomaly as a function of carbonate content migrates in the direction of higher carbonate values in the deeper part of the section, producing an apparently linear positive relationship at the chalk/limestone transition (850-928 mbsf). Curves are second-order polynomial fits to the data, with the exception of a linear fit to the last panel.

impedance profile in the more deeply buried Ceara Rise section, but a full model of the impedance structure should consider the parabolic form of the carbonate-bulk density relation as well.

\section{Seismic Anisotropy}

Variations in anisotropy reflect differences in sediment fabric and the mechanical coupling of sediment particles. The anisotropy is a percentage measure:

$$
A_{p}=200 \times\left(V_{p t}-V_{p l}\right) /\left(V_{p t}+V_{p l}\right),
$$

(Carlson and Christensen, 1977), where $V_{p t}$ is the measured transverse velocity, and $V_{p l}$ is the longitudinal (along core length) velocity. Positive values indicate transverse velocities greater than longitudinal. As we have observed with other physical properties, carbonate content exerts a first-order control on seismic anisotropy. In addition, there is an evolving component to anisotropy that is driven by depth-related compaction trends. The general trend we observe is for initial anisotropies to be nearly zero, to shift then to systematically negative values (longitudinal velocity greater than transverse) by about 100-m burial depth, and last to show a gradual evolution to positive anisotropy (transverse velocities greater than longitudinal) from about $150 \mathrm{mbsf}$ to total depth. The deeper trend suggests that preferred particle alignment in the horizontal sense proceeds relatively rapidly with depth. We observe that the depth dependence of transverse velocity is significantly stronger in slope and correlation coefficient than that of longitudinal velocities.

Different modes of compaction show up clearly in plots of anisotropy as a function of carbonate content (Fig. 11). Below $300 \mathrm{~m}$, anisotropy at Hole 925A follows a curvilinear trend. Second-order polynomial fits give correlation coefficients of 0.7-0.9. More calcareous layers are clearly more isotropic than are more clay-rich beds, and the difference becomes accentuated with further compaction (compare, for example, the magnitude of anisotropy differences between samples from 300 to 374 mbsf and from 800 to 850 mbsf; Fig. 11). This pattern is superimposed on the general trend of increasingly positive anisotropy with depth. We interpret the data as the result of the competition between mechanical compaction, which is most efficient in clay-rich layers, and chemical compaction, which is promot- 

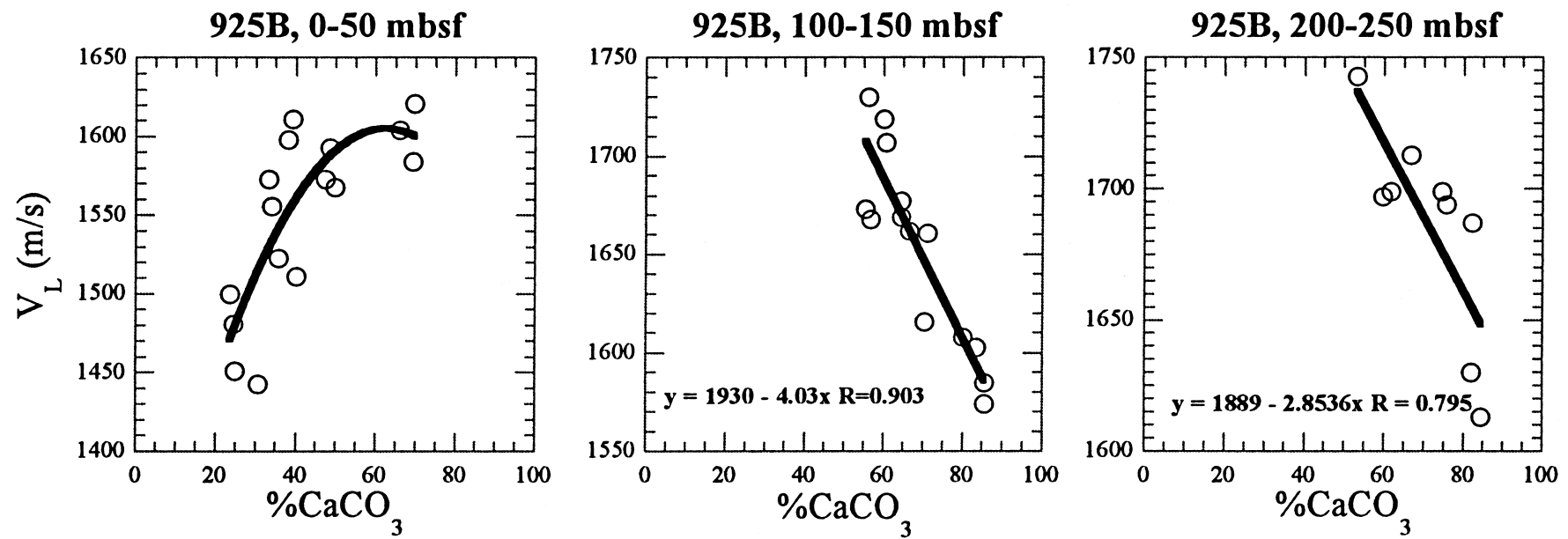

Figure 7. Changing dependency of longitudinal velocity (uncorrected) with carbonate content at Hole 925B. Note that the initial relation is positive (and perhaps curvilinear), but that after burial to $100 \mathrm{mbsf}$, velocity becomes clearly negatively correlated with carbonate content. Between 50 and 100 mbsf, almost no correlation is present between velocity and lithology, as the onset of compaction rearranges the initial velocity-carbonate relationship. A similar transition zone occurs between 250 and 300 mbsf before the next change in velocity-carbonate relations shown in Figure 8
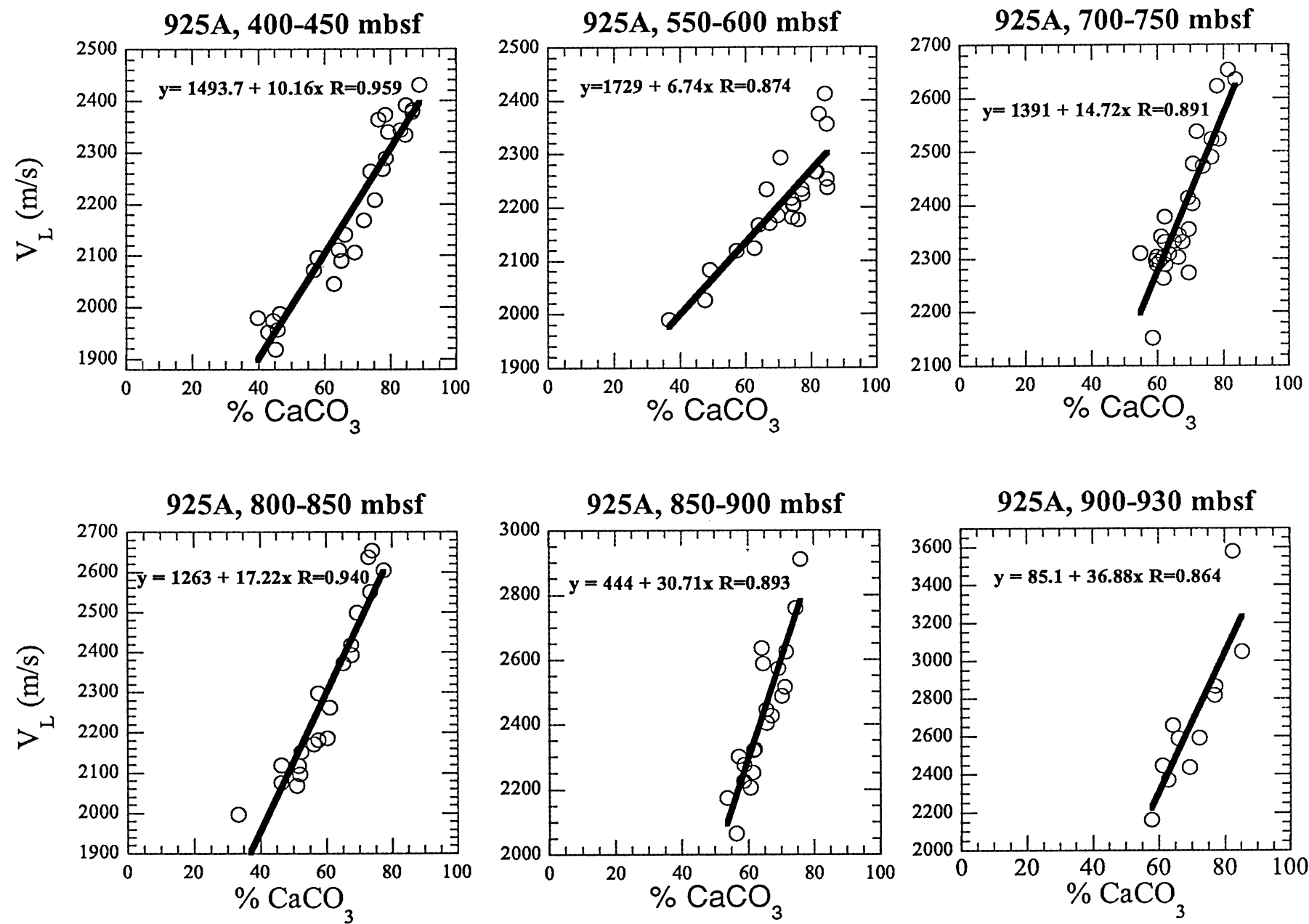

Figure 8. Evolution of longitudinal (along core axis) velocities (corrected for calibration error discussed in text, but not corrected to in situ conditions) as a function of carbonate content at Hole 925A. Note a progressive increase in slope with burial, attributed in text to a progressive increase in chemical compaction of highly calcareous strata. 


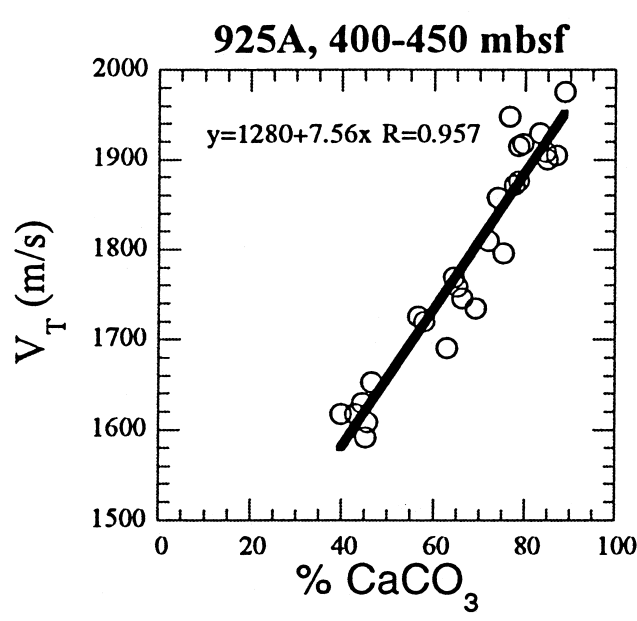

925A, 800-850 mbsf

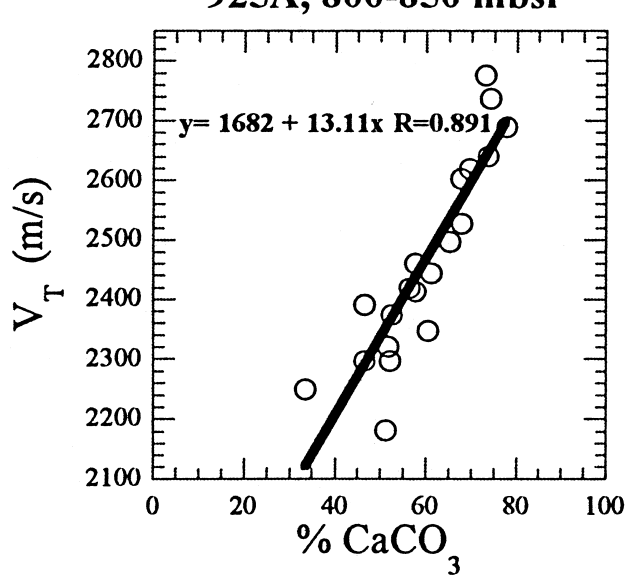

925A, 550-600 mbsf

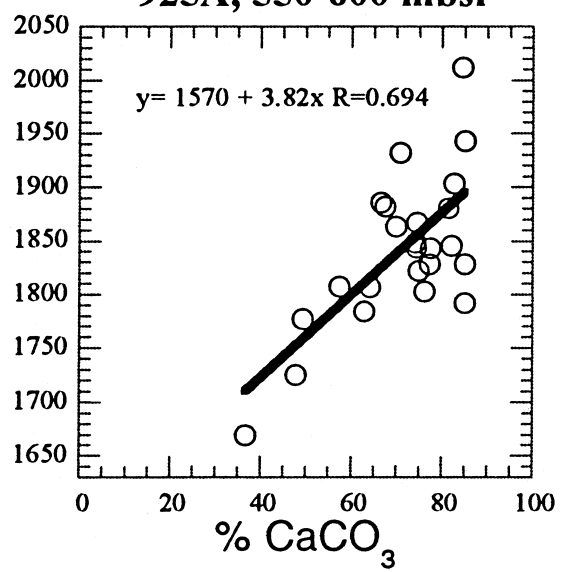

925A, 850-900 mbsf

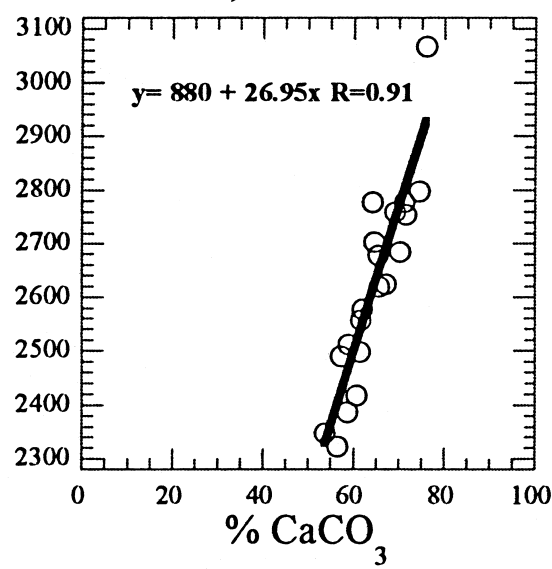

925A, 700-750 mbsf

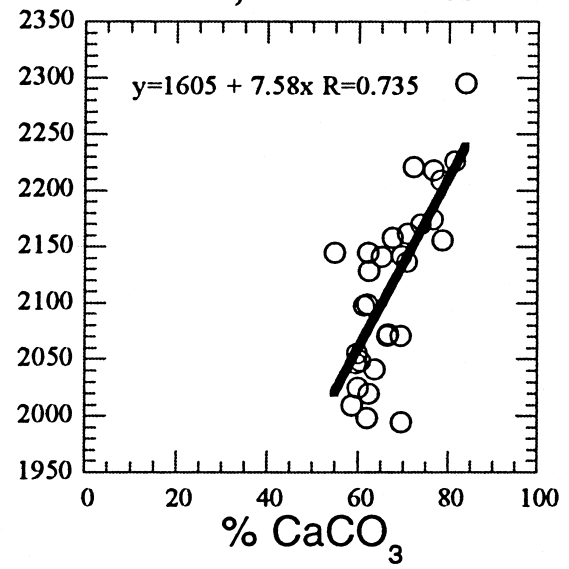

925A, 900-930 mbsf

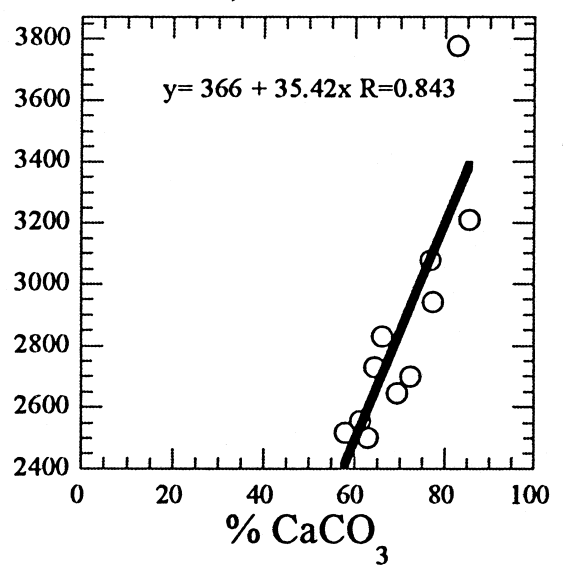

Figure 9. Evolution of transverse velocities (corrected for calibration error discussed in text, but not corrected to in situ conditions) as a function of carbonate content at Hole 925A. Transverse velocities show less dependency on carbonate content than do longitudinal velocities (see Fig. 8), but a similar pressure-solution relation to carbonate content.
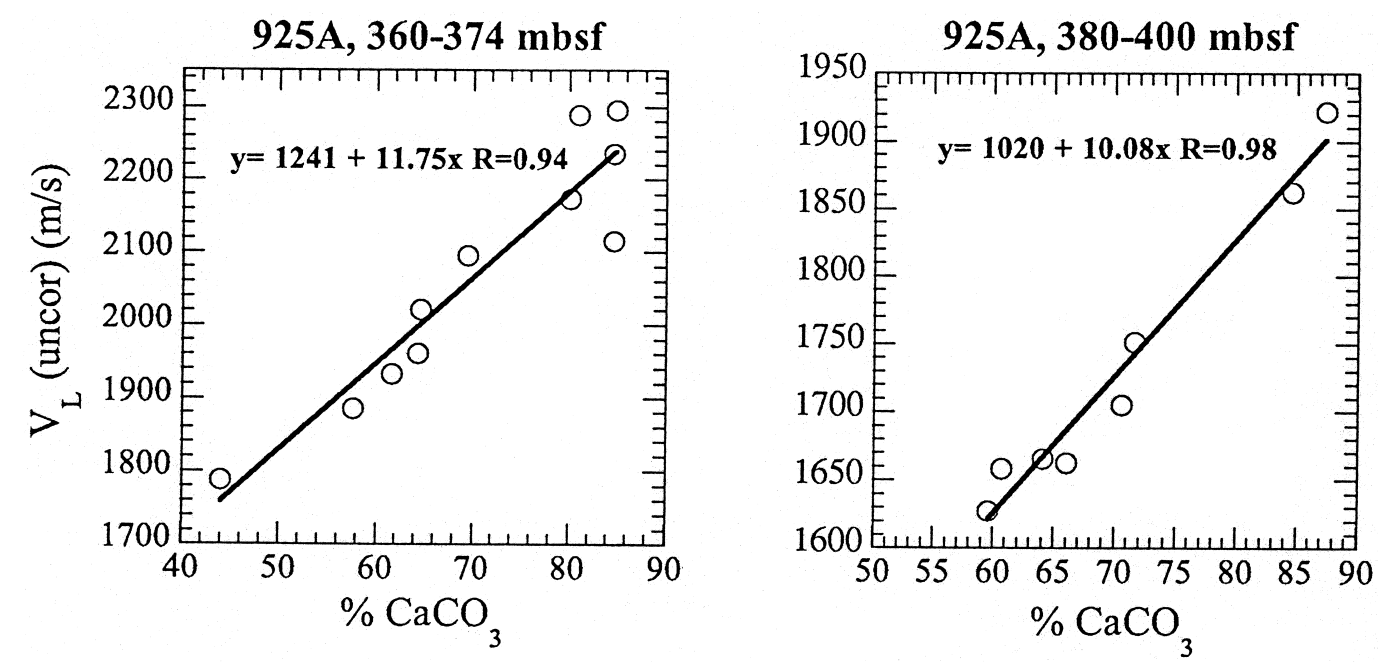

Figure 10. Regression equations used to estimate the correction to Hole 925A shipboard velocity measurements from Cores 154-925A-11R through 50R. 
ed in carbonate-rich beds. Where mechanical compaction dominates, preferred orientation of clay particles gives rise to transverse velocities significantly higher than longitudinal. Where pressure-solution is an important process, the seismic fabric is more nearly isotropic. Note that at equivalent burial depths, both transverse and longitudinal velocities are lower in clay-rich strata than in high carbonate zones, indicating a poorer mechanical coupling of grains in clay-rich layers.

\section{DISCUSSION}

Physical properties data from Leg 154 follow structured patterns as a function of lithology and depth. An uninterrupted oscillation of lithologies has allowed us to deduce the evolution of physical properties over a range of carbonate contents from $30 \%$ to $90 \%$, to a burial depth of $900 \mathrm{~m}$. We have shown that calcium carbonate content can explain most of the variance in the evolution of density/porosity and seismic behavior of Ceara Rise sediments. However, it is important to emphasize that the behavior of the other end-member in a twocomponent mixing system helps to determine the slope and variance of carbonate/physical properties data. Specifically, the unusually high (for pelagic sediments) quartz content of the noncarbonate fraction is responsible for enhanced shallow mechanical compaction at Ceara Rise, and hence for different bulk density relationships to carbonate content from those frequently observed in near-surface pelagic sections (cf. Herbert and Mayer, 1991). The results presented here are most likely valid for other carbonate-terrigenous provinces with similar quartz percentages, but they should not be extrapolated to dissimilar pelagic sedimentary sequences.

The sense of the physical properties variations with respect to lithology may change over relatively narrow transition zones. We have termed these depth-related shifts inversions. Because each type of measurement captures a slightly different combination of depositional and compactional processes, the changes in physical propertiescarbonate relationships do not occur at precisely the same depth. Bulk density, for example, becomes negatively correlated with carbonate content by about $40 \mathrm{mbsf}$ on Ceara Rise, whereas seismic velocities do not show a similar switch until about $100 \mathrm{~m}$ burial depth.

The dependence of physical properties on both lithology and burial depth has some important implications for physical properties sampling. We have seen that it would be incorrect to assume that measurements taken in one compactional regime can be extrapolated to another. For example the bulk density-carbonate relationship typical of depths from 300 to $700 \mathrm{mbsf}$ at Site 925 would be a poor model for the next $200 \mathrm{~m}$. And we have also seen that physical properties trends are complex enough to require that the full range of lithologies be sampled. It would thus be poor strategy to sample randomly, or only in "average" lithologies, in a highly oscillatory sediment column such as that of the Ceara Rise. It is only possible to accurately define physical properties trends, and therefore to understand better the physical and chemical processes occurring during compaction, by deliberately analyzing the entire range of lithologies encountered. The situation is analogous to that faced by paleoceanographers investigating records paced by "Milankovitch" fluctuations, where aliasing caused by inadequate sampling density is well recognized (Pisias and Mix, 1988).

The order in relations between physical properties and sediment type observed on the Ceara Rise and elsewhere does suggest good prospects for developing a better predictive understanding of the physical and chemical evolution of pelagic sediments. From such predictive models, we can hope to improve procedures for interpreting remotely extracted information such as borehole logs and seismic data. Results from Ceara Rise suggest that paleoceanographic variations in sediment composition, determined in large part by paleoclimatic variations (see various contributions in this volume) will drive significant physical properties changes with depth. The simplest of the lithologic variables to measure is carbonate content, which has a distinguished track record in paleoceanography. In detail, other paleoceanographic changes in sedimentation can affect physical properties significantly. For example, the middle Miocene and early Oligocene siliceous intervals seen at Site 929 produce pronounced drops in bulk density and seismic velocities (Curry, Shackleton, Richter, et al., 1995). It is important to recognize, however, that the influence of lithology on physical properties may be felt not only through primary (uncompacted) conditions set at deposition, but by a long history of mechanical and chemical alteration with depth.

\section{REFERENCES}

Bachman, R.T., 1984. Intratest porosity in foraminifera. J. Sediment. Petrol., 54:257-262.

Bassinot, F.C., Marsters, J.C., Mayer, L.A., and Wilkens, R.H., 1993. Variations of porosity in calcareous sediments from the Ontong Java Plateau. In Berger, W.H., Kroenke, L.W., Mayer, L.A., et al., Proc. ODP, Sci. Results, 130: College Station, TX (Ocean Drilling Program), 653-661.

Berner, R.A., 1980. Early Diagenesis: A Theoretical Approach: Princeton, NJ (Princeton Univ. Press).

Boyce, R.E., 1976. Definitions and laboratory techniques of compressional sound velocity parameters and wet-water content, wet-bulk density, and porosity parameters by gravimetric and gamma-ray attenuation techniques. In Schlanger, S.O., Jackson, E.D., et al., Init. Repts. DSDP, 33: Washington (U.S. Govt. Printing Office), 931-958.

Carlson, R.L., and Christensen, N.I., 1977. Velocity anisotropy and physical properties of deep-sea sediments from the western South Atlantic. In Supko, P.R., Perch-Nielsen, K., et al., Init. Repts. DSDP, 39: Washington (U.S. Govt. Printing Office), 555-559.

Curry, W.B., Shackleton, N.J., Richter, C., et al., 1995. Proc. ODP, Init. Repts., 154: College Station, TX (Ocean Drilling Program).

Fulthorpe, C.S., Schlanger, S.O., and Jarrard, R.D., 1989. In situ acoustic properties of pelagic carbonate sediments on the Ontong Java Plateau. $J$. Geophys. Res., 94:4025-4032.

Hagelberg, T.K., Pisias, N.G., Mayer, L.A., Shackleton, N.J., and Mix, A.C., 1995. Spatial and temporal variability of late Neogene equatorial Pacific carbonate: Leg 138. In Pisias, N.G., Mayer, L.A., Janecek, T.R., PalmerJulson, A., and van Andel, T.H. (Eds.), Proc. ODP, Sci Results, 138: College Station, TX (Ocean Drilling Program), 321-336.

Hamilton, E.L., 1974. Prediction of deep-sea sediment properties: state of the art. In Inderbitzen, A.L. (Ed.), Deep-Sea Sediments: Physical and Mechanical Properties: New York (Plenum), 1-44.

, 1976. Variations of density and porosity with depth in deep-sea sediments. J. Sediment. Petrol., 46:280-300.

Herbert, T.D., Burnett, C., and Tom, B.A., 1992. Precise major component determinations in deep-sea sediments using Fourier Transform Infrared Spectroscopy. Geochim. Cosmochim. Acta, 56:1759-1763.

Herbert, T.D., and Mayer, L.A., 1991. Long climatic time series from sediment physical property measurements. J. Sediment. Petrol., 61:10891108.

Lyle, M., and Dymond, J., 1976. Metal accumulation rates in the southeast Pacific: errors introduced from assumed bulk densities. Earth Planet. Sci. Lett., 30:164-168.

Marsters, J.C., Resig, J.M., and Wilcoxon, J.A., 1993. Relationships between physical properties and microfossil content and preservation in calcareous sediments of the Ontong Java Plateau. In Berger, W.H., Kroenke, L.W., Mayer, L.A., et al., Proc. ODP, Sci. Results, 130: College Station, TX (Ocean Drilling Program), 641-652.

Mayer, L.A., 1979. Deep sea carbonates: acoustic, physical, and stratigraphic properties. J. Sediment. Petrol., 49:819-836.

, 1991. Extraction of high-resolution carbonate data for paleoclimate reconstruction. Nature, 352:148-150.

Mienert, J., 1984. The importance of carbonate content in the acoustic stratigraphy of Panama Basin. Mar. Geol., 54:237-247.

Nobes, D.C., 1989. A test of a simple model of the acoustic velocity in marine sediments. J. Acoust. Soc. Am., 86:290-294.

Nobes, D.C., Langseth, M.G., Kuramoto, S., and Holler, P., 1992. Identification and correction of a systematic error in index property measurements. In Tamaki, K., Suyehiro, K., Allan, J., McWilliams, M., et al., Proc. ODP, Sci. Results, 127/128 (Pt. 2): College Station, TX (Ocean Drilling Program), 985-1015.

Nobes, D.C., Mienert, J., and Dirksen, G.J., 1991. Lithologic control of physical-property interrelationships. In Ciesielski, P.F., Kristoffersen, Y., et 
al., Proc. ODP, Sci. Results, 114: College Station, TX (Ocean Drilling Program), 657-669.

O'Brien, D.K., and Manghnani, M.H., 1992. Physical properties of Site 762: a comparison of shipboard and shore-based laboratory results. In von Rad, U., Haq, B.U., et al., Proc. ODP, Sci. Results, 122: College Station, TX (Ocean Drilling Program), 349-362.

Pisias, N.G., and Mix, A.C., 1988. Aliasing of the geologic record and the search for long-period Milankovitch cycles. Paleoceanography, 3:613619.

Rack, F.R., and Palmer-Julson, A., 1992. Sediment microfabric and physical properties record of late Neogene Polar Front migration, Site 751. In Wise, S.W., Jr., Schlich, R., et al., Proc. ODP, Sci. Results, 120: College Station, TX (Ocean Drilling Program), 179-205.
Taylor, E., 1991. Physical properties and consolidation of the calcareous sediments of Broken and Ninetyeast Ridges. In Weissel, J., Peirce, J., Taylor, E., Alt, J., et al., Proc. ODP, Sci. Results, 121: College Station, TX (Ocean Drilling Program), 253-260.

Wilkens, R.H., and Handyside, T., 1985. Physical properties of equatorial Pacific sediments. In Mayer, L., Theyer, F., Thomas, E., et al., Init. Repts. DSDP, 85: Washington (U.S. Govt. Printing Office), 839-847.

Date of initial receipt: 8 December 1995

Date of acceptance: 16 April 1996

Ms 154SR-131
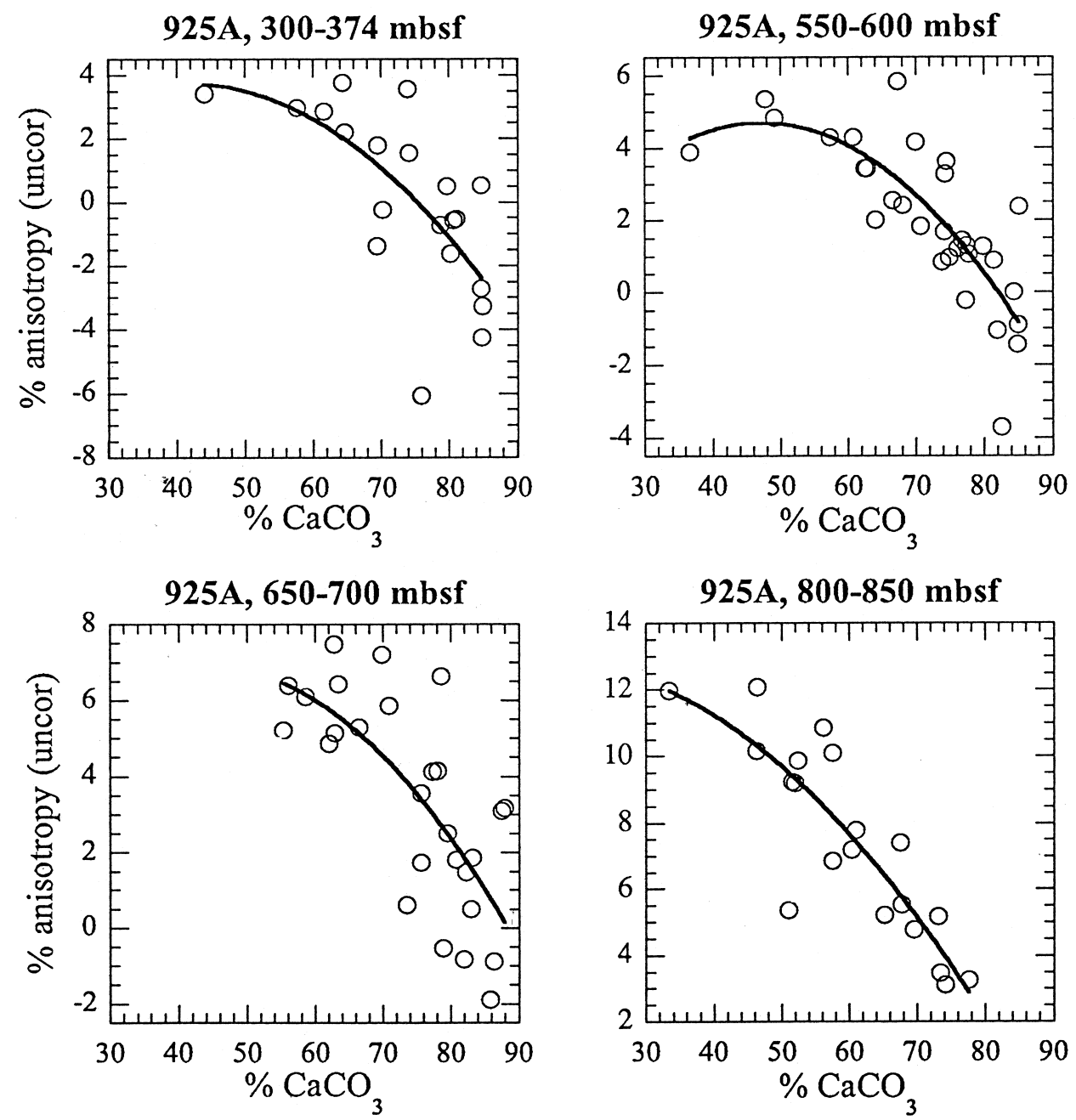

Figure 11. Seismic anisotropies as a function of measured carbonate content and depth, Hole 925A. Positive anisotropy denotes transverse velocity greater than longitudinal, and negative anisotropy denotes reverse. Note in each case a general curvilinear trend and the gradual evolution to more positive anisotropies with depth, as mechanical compaction produces more strongly aligned fabrics. However, at any given depth range, velocities in more calcareous strata are more nearly isotropic. 